\title{
Vertical structure of atmosphere in pre-monsoon season over Bangalore
}

\author{
Geeta Agnihotri ${ }^{1, *}$ and A P Dimri ${ }^{2}$ \\ ${ }^{1}$ Meteorological Centre, India Meteorological Department, Bangalore 560 001, India. \\ ${ }^{2}$ School of Environmental Sciences, Jawaharlal Nehru University, New Delhi 110 067, India. \\ *Corresponding author.e-mail: g.agnihotri@imd.gov.in; geetag54@yahoo.com
}

This paper discusses the variation of dry bulb and dew point temperature ( $T$ and $\left.T_{d}\right)$ on the days with and without thunderstorm (TSD and NTSD) over Bangalore during pre-monsoon season. The thermodynamic parameters like convective available potential energy (CAPE), convective inhibition energy (CIN), precipitable water content (PWC) and dynamical parameter vertical wind shear difference (VWS) are studied. The mean profiles of $\mathrm{T}, \mathrm{T}_{\mathrm{d}}$ are generated using March-May upper air data of 1730 hrs IST from 2000-2007 for Bangalore. These are also generated on the TSD and NTSD respectively. It is found that the difference between mean profile of T for TSD/NTSD and seasonal mean is negative/positive till $200 \mathrm{hPa}$. On the other hand, the difference of the seasonal mean of $\mathrm{T}_{\mathrm{d}}$ and that of $\mathrm{T}_{\mathrm{d}}$ on the TSD/NTSD is found to be positive/negative till $300 \mathrm{hPa}$. These results are found to be significant at $99 \%$ confidence. It is found that $\mathrm{T}$ is less than the mean at surface till $600 \mathrm{hPa}$ on TSD, whereas it is $0.5^{\circ} \mathrm{C}$ above average on the NTSD respectively. The difference between the $T_{d}$ on the TSD and mean $T_{d}$ is of the order of $3-5^{\circ} \mathrm{C}$ till $300 \mathrm{hPa}$. On the NTSD, this difference ranges between -1 and $-2^{\circ} \mathrm{C}$ in the entire troposphere. The mean values of CAPE, CIN, PWC and VWS for Bangalore in pre-monsoon season are found to be $1324,49.3 \mathrm{~J} / \mathrm{kg}, 30 \mathrm{~mm}$ and $-0.0007 \mathrm{~s}^{-1}$, respectively. These parameters were used as predictors for forecasting a thunderstorm. The critical success index and Heidke skill score were used for evaluating the forecast skill of the above parameters for 2 years from 2008 to 2009. CAPE and PWC are able to distinguish a TSD from that of a NTSD with $99 \%$ confidence. It is found that these scores are 0.44 and 0.35 for CAPE and 0.49 and 0.53 for precipitable water content.

\section{Introduction}

Thunderstorms are mesoscale systems that are known to have profound socio-economic impact. These clouds are driven by buoyancy and vary in terms of the degree of organisation. Sometimes they are in the form of single or multicell clusters, or in the form of super cell or a squall line. Each of the above type of thunderstorm is formed under a set of unique environmental conditions of instability and wind shear. The thunderstorm cells often extend to a height of $10-12 \mathrm{~km}$ in the vertical and result in heavy rainfall, lightening, hail and squally winds and severe weather. They are a hazard for aviation, agriculture and are known to leave a trail of destruction behind. Dry thunderstorms are equally powerful and can lead to the outbreak of wild fires by generating heat from cloud to ground lightening. The super cells and squall lines are capable of causing far more destruction.

Occurrence of thunderstorms with varying numbers and intensity is a characteristic feature over the entire Indian region annually. But during the pre-monsoon season (March-May), the

Keywords. Thunderstorm; CAPE; CIN; PWC; wind shear difference. 
thunderstorms are maximum in terms of number and severity over the north-east India, West Bengal region and adjoining Indo-Gangetic plains and Bangladesh region. Super cells too are observed sometimes in this region (Sinha and Pradhan 2006) and hence thunderstorms are popularly called as Nor'westers or KalBaishakhi. The severity of the storms in these regions is due to the presence of moist southerly winds from Bay of Bengal in lower levels and westerlies/north-westerlies of continental origin in the upper levels which enhances the instability (Srinivasan et al. 1973). The southwestern part of Indian peninsula is the second highest zone to experience thunder activity during this season. Two important mountain ranges in southern India which are located very close to sea shores are Western and Eastern Ghats. The rest of it is a plateau land which slopes eastwards. The landmass during this season gets heated and the synoptic systems like north-south trough/wind discontinuity from central India to southern peninsula in lower levels act to enhance the instability. The two anticyclones over the Indian seas are the source of moisture supply for southern peninsula. These factors result in severe thunderstorms over this region. The seasonal frequency of thunderstorms over the peninsular India ranges from 20 to 40 during pre-monsoon (Tyagi 2007). Studies about thunderstorms are focussed around the climatological aspects over the stations and regions (Brooks et al. 2003; Singh et al. 2011), favourable synoptic situations that lead to their formation (Yamane et al. 2012), changes in the atmospheric parameters during their life cycle (Tyagi et al. 2013), evaluation of the stability indices along with their thresholds (Yamane et al. 2010; Agnihotri 2014), study of their structure using satellite, radar (Mukhopadhyay et al. 2009; Latha and Murthy 2011) and simulations using sophisticated numerical models (Rajeevan et al. 2010; Fadnavis et al. 2014; Pennelly et al. 2014). Various research projects have been taken up time to time for studying one of the above aspects of thunderstorms over the northeastern region of India (Yamane and Hayashi 2006; Chakrabarti et al. 2008; Dalal et al. 2012; Litta et al. 2012; Das et al. 2014).

This study aims at finding out the differences in basic atmospheric variables on the thunderstorm (TSD) and non-thunderstorm days (NTSD) over Bangalore city, a station in interior southern peninsular India (marked by a circle in figure 1). This city is located in the southeastern part of Deccan plateau and lies in the arid to semi-arid region of peninsular India. It experiences severe thunderstorms during pre-monsoon season which are accompanied with occassional hails. The difference in thermodynamic and dynamic parameters on the TSD and NTSD are also examined in order to understand the role played by these parameters in thunderstorm generation over Bangalore. To summarise, following are the goals of this study:

- How the vertical variation of the dry bulb $(\mathrm{T})$ and dew point $\left(\mathrm{T}_{\mathrm{d}}\right)$ temperature is different on a day with thunder (TSD) from that of non-thundery day (NTSD) over Bangalore and whether this difference is significant?

- What are the quantitative ranges of thermodynamic parameters like convective available potential energy (CAPE), convective inhibition energy (CIN) and precipitable water content (PWC) for TSD and NTSD over Bangalore? Whether this difference is significant?

- What is the quantitative range of dynamical parameter vertical wind shear (VWS) for TSD and for NTSD over Bangalore? Whether this difference is significant?

- Whether these parameters can be used for forecasting?

\section{Data and methodology}

In an effort to understand the difference in basic atmospheric variables during pre-monsoon season, the weather remarks of two stations namely, Bangalore city $\left(43295,12.98^{\circ} \mathrm{N} / 77.58^{\circ} \mathrm{E}, 921 \mathrm{~m}\right.$ amsl) and Bangalore airport $\left(43296,12.51^{\circ} \mathrm{N} / 78.31^{\circ} \mathrm{E}\right.$, $888 \mathrm{~m}$ amsl) are taken from the monthly meteorological registers (MMRs). These two observatories are class I observatories, about $14 \mathrm{~km}$ apart and keep a check on weather $24 \times 7$ and the surface data is recorded every $3 \mathrm{hr}$. The data for a period of 10 years from 2000 to 2009 is taken. The average sounding at each level is arrived at by taking the mean of $\mathrm{T}\left(\mathrm{T}_{\mathrm{d}}\right)$ for each level during 2000-2007 and is called as $\mathrm{T}_{\text {ave }}\left(\mathrm{T}_{\text {dave }}\right)$. Similarly, the average sounding on TSD (NTSD) is computed by taking the average of $\mathrm{T}$ and $\mathrm{T}_{\mathrm{d}}$ on all such days. A day is considered as a TSD if any of these two stations report thunder. Further, if thunder is reported between 0430 and $1629 \mathrm{hr}$ IST (Indian Standard Time) (1630 and $0429 \mathrm{hr}$ IST of the next day), then the upper air data at 0530 (1730) $\mathrm{hr}$ IST is used for making composite profiles of $\mathrm{T}$ and $\mathrm{T}_{\mathrm{d}}$. The $\pm 1 \mathrm{hr}$ window from the actual time of observation is taken so that data can be used for operational forecasts.

During the years 2000-2007, there were a total of 736 days in pre-monsoon season and out of these, on $45(\sim 6 \%)$ and $155(\sim 21 \%)$ days, thunderstorm was reported between 0430-1629 and 1630-0429 hr IST respectively. Most of the thunderstorms occur in the afternoon or evening times over this station (Agnihotri et al. 2013). The composites of $\mathrm{T}$ and $\mathrm{T}_{\mathrm{d}}$ are made using 120 days of available data out of a total of 155 TSDs. 


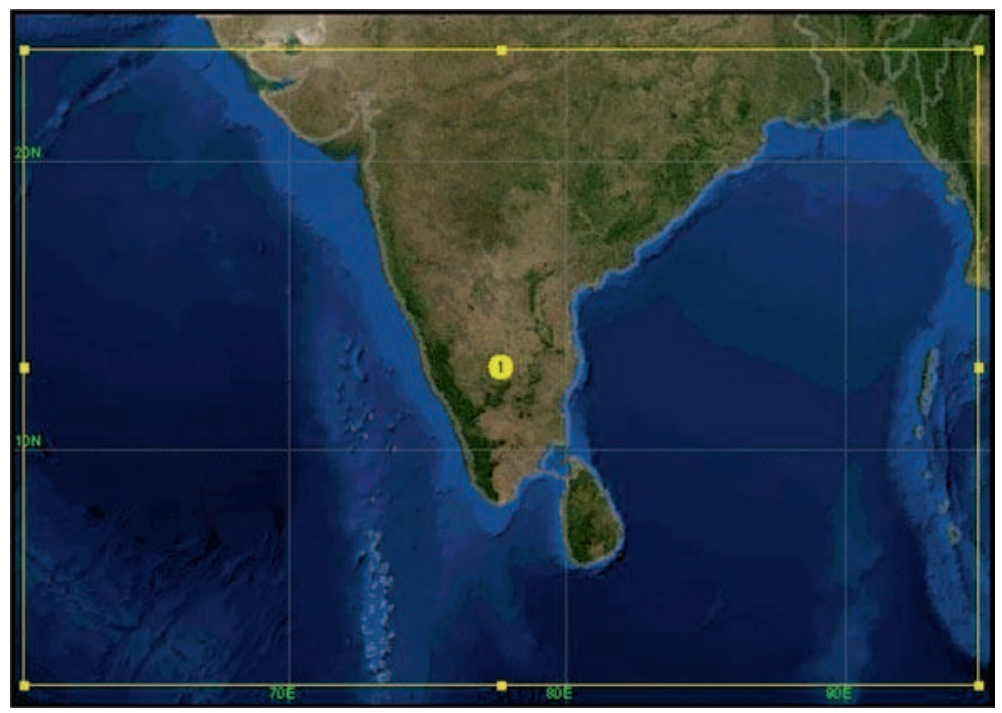

Figure 1. Location of Bangalore shown by '1'.

There are several parameters that are used to evaluate the severe and convective weather potential of the atmosphere such as lifted index (LI), $\mathrm{K}$ index, total total index (TTI), SWEAT (Severe weather threat), Showalter's and modified Showalter's index (SHI and $\mathrm{SHI}_{\mathrm{m}}$ ), humidity index (HI), CAPE, CIN, PWC, etc. The potential of first few namely, K, TTI, SLI (Showalter index), HI, DCI, $\mathrm{SHI}$ and $\mathrm{SHI}_{\mathrm{m}}$, BI (Boyden) and SWEAT in predicting the TS and NTS days over Bangalore was taken up in an earlier study (Agnihotri 2014). It was found that more than one index has to be used for predicting a TSD from an NTSD. Also, when these indices are used for prediction, it leads to low values of skill scores showing that these have limited capability in predicting a TSD. This is because they are unable to provide the complete characterisation of the atmosphere as they use either the lower or middle level temperature, humidity and wind values to represent the state of the atmosphere in the entire column which is not the case in reality. But CAPE (Moncrieff and Miller 1976), on the other hand, has gained popularity because it is a measure moist convective instability throughout the troposphere. It is the positive area on the T- $\Phi$ gram which is proportional to buoyant energy that a parcel possesses. Similarly, CIN (negative area) is the measure of the energy that is required to lift the parcel from surface to level of free convection (LFC). The PWC is amount of moisture present in an atmospheric column. These are better representatives of the state of atmosphere as they are vertically integrated quantities. These parameters were taken from University of Wyoming website (http://weather.uwyo.edu/upperair/sounding. html) for the period under consideration. The dynamical parameter VWS was calculated using the procedure mentioned in Chaudhari et al.
(2010). All above-motioned parameters were analysed for TSD and NTSD based on $1730 \mathrm{hr}$ IST ascents only. The above-mentioned parameters for 2008-2009 are used for testing the forecasts.

The soundings having CAPE equal to zero have been neglected because this implies that $\mathrm{P}_{\mathrm{LFC}}$ has not reached at all. The diurnal variation of thermodynamic parameters is discussed but the composites are only based on $1730 \mathrm{hr}$ IST observations only.

\subsection{Statistical test}

The $Z_{x y}$ test (Wilks 1995) is used for accepting or rejecting the null hypothesis. This is used to find out if the difference between the means of two independent samples is significant or not and is given by the formula

$$
Z=\frac{\left(M_{x}-M_{y}\right)}{\sqrt{\frac{s_{d x}^{2}}{n_{x}}}+\sqrt{\frac{s_{d y}^{2}}{n_{y}}}},
$$

where $M_{x}, M_{y}, s_{d x}$ and $s_{d y}$ are the mean and standard deviations of the meteorological parameter on TSD and NTSD respectively. $n_{x}$ and $n_{y}$ are the numbers of TSD and NTSD respectively. The value of $Z_{x y}$ in the range of \pm 1.96 and \pm 2.58 are used for the confidence interval of $95 \%$ and $99 \%$, respectively. In this study, $Z_{x y}$ was computed for $\mathrm{T}$ and $\mathrm{T}_{\mathrm{d}}$ at the surface and at other levels in the vertical with $x$ and $y$ as TSD and NTSD, respectively.

\section{Results and discussions}

\subsection{Dry bulb $(T)$ and dew point temperature $\left(T_{d}\right)$}

The difference of mean sounding on the TSD and NTSD from the mean sounding of the entire period $\left(\mathrm{T}_{\text {ave }}\right)$ is denoted by $\mathrm{T}_{\mathrm{x}}-\mathrm{T}_{\text {ave }}$ and $\mathrm{T}_{\mathrm{y}}-\mathrm{T}_{\text {ave }}$ and are 
plotted in figure 2(a). The profiles of $T_{x}-T_{\text {ave }}$ and $\mathrm{T}_{\mathrm{y}}-\mathrm{T}_{\text {ave }}$ show that positive anomaly of temperature is associated with NTSD throughout the troposphere, whereas negative anomaly is associated with the TSD. The atmosphere cools in the entire troposphere with significant cooling in the lower troposphere on the TSD (figure 2c). The temperature difference is negative (positive) throughout

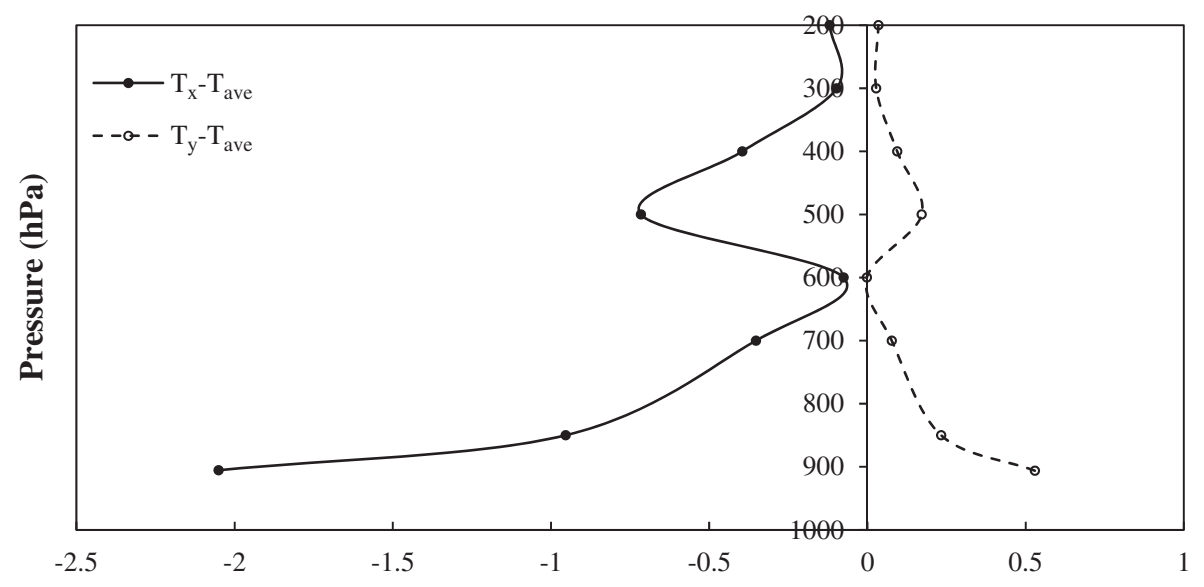

(a)

$\mathrm{T}-\mathrm{T}_{\mathrm{ave}}\left({ }^{\circ} \mathrm{C}\right)$

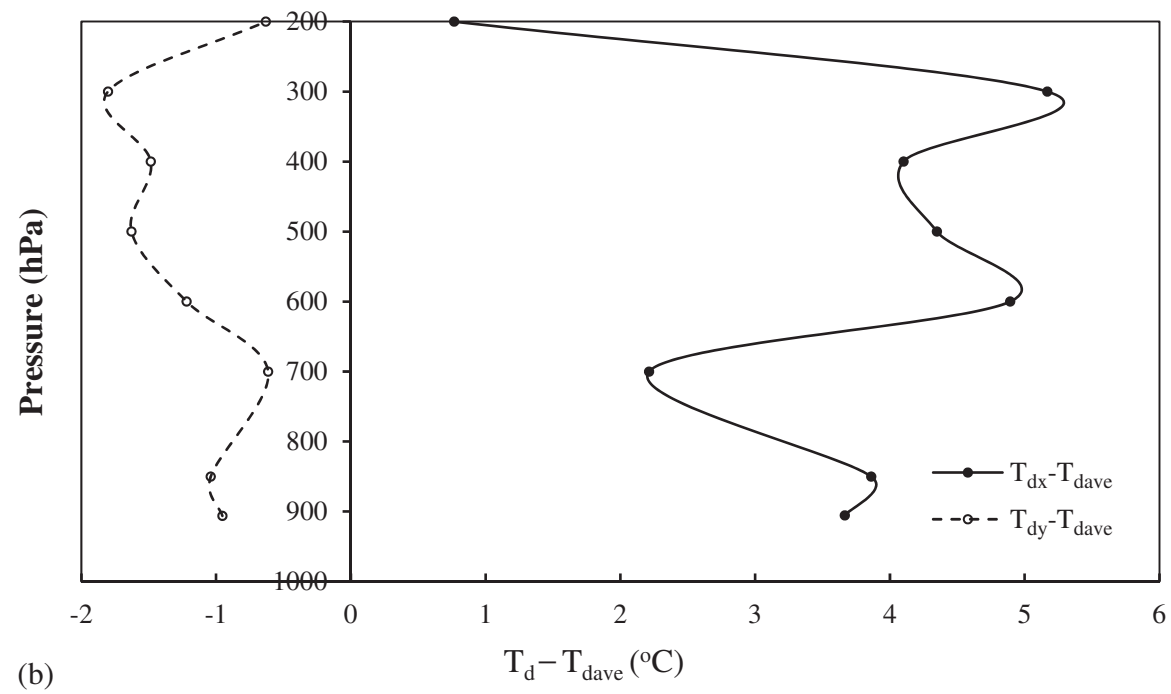

(b)

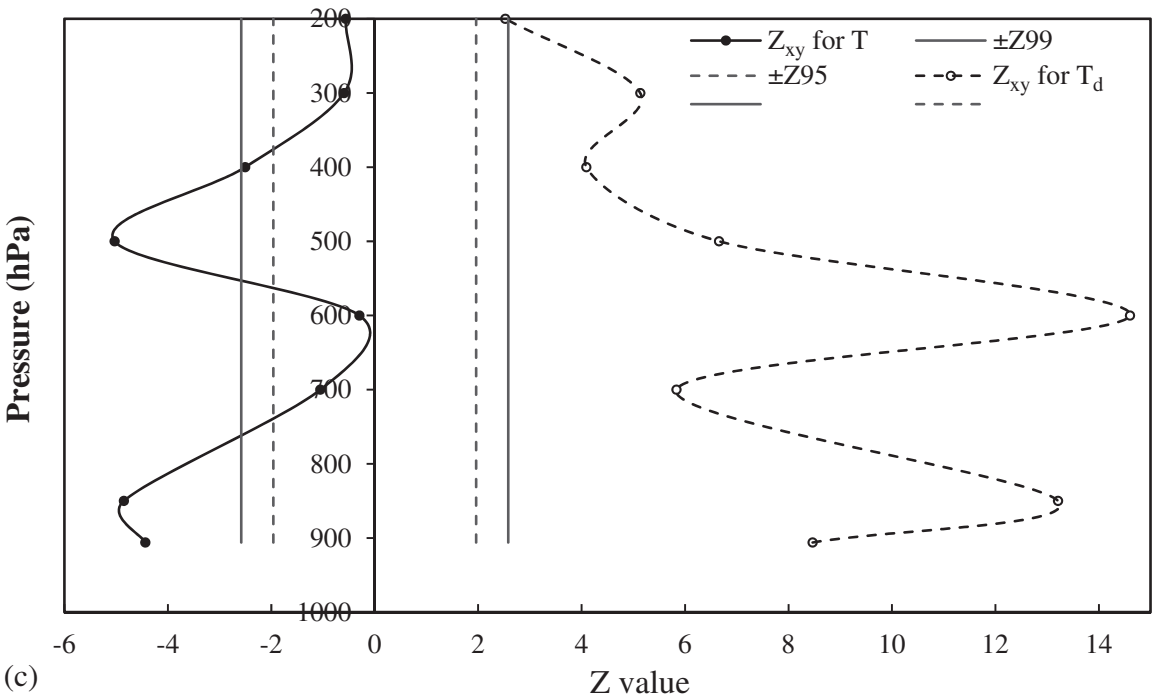

Figure 2. Plot of difference of mean (a) temperature on TSD $\left(\mathrm{T}_{\mathrm{x}}\right)$; NTSD $\left(\mathrm{T}_{\mathrm{y}}\right)$ and $\mathrm{T}_{\text {ave }}$, (b) dew point temperature on $\operatorname{TSD}\left(\mathrm{T}_{\mathrm{dx}}\right)$; NTSD $\left(\mathrm{T}_{\mathrm{dy}}\right)$ and $\mathrm{T}_{\text {dave }}$ during 2000-2007, (c) $Z_{x y}$ for $\mathrm{T}$ and $\mathrm{T}_{\mathrm{d}}$. 
the troposphere on the TSD (NTSD) respectively. At the surface maximum -ve and +ve departures on TSD and NTSD are 2 and $0.5^{\circ} \mathrm{C}$ respectively. The $Z_{x y}$ values for $\mathrm{T}$ at each level are shown in figure 2(c). This shows that the difference in $\mathrm{T}_{\mathrm{x}}$ and $\mathrm{T}_{\mathrm{y}}$ is statistically significant at $99 \%$ confidence from the surface till $850 \mathrm{hPa}$.

The plot of difference of mean dew point temperature sounding on the TSD $\left(\mathrm{T}_{\mathrm{dx}}\right)$ and NTSD $\left(\mathrm{T}_{\mathrm{dy}}\right)$ and mean soundings $\left(\mathrm{T}_{\text {dave }}\right)$ are represented by $T_{d x}-T_{\text {dave }}$ and $T_{d y}-T_{\text {dave }}$ and are plotted in figure $2(\mathrm{~b})$. The variation of $\mathrm{T}_{\mathrm{d}}$ for TSD is opposite to that of the variations in $\mathrm{T}$ throughout the troposphere. Strong and +ve anomaly in $T_{d}$ is present on the TSDs throughout the troposphere favouring the occurrence of thunderstorms. Maximum anomaly in $\mathrm{T}_{\mathrm{d}}$ is present in the middle troposphere. The -ve anomaly is observed throughout the troposphere on NSTD respectively. The $Z_{x y}$ values at each level for $T_{d}$ are shown in figure $2(\mathrm{c})$. The difference of $T_{d}$ on TSD and NTSD is statistically significant up in the entire troposphere. The presence of large amounts of water vapour in the atmosphere makes the air more buoyant favouring

Table 1. Observed range of thermodynamic parameters at 1730 hr IST over Bangalore during 2000-2007.

\begin{tabular}{llllll}
\hline Sl. no. & & Mean & Std. dev. & Max & \multicolumn{1}{c}{ Min } \\
\hline 1 & CAPE (J/kg) & 1324 & 1382 & 8409.5 & 0.02 \\
2 & CIN (J/kg) & 49.3 & 94.8 & 1220 & 0 \\
3 & PWC (mm) & 30 & 11.0 & 60.7 & 1.4 \\
4 & VWS ( $\left.{ }^{-1}\right)$ & -0.0007 & 0.0053 & 0.035 & -0.027 \\
\hline
\end{tabular}

the air parcel to raise more as compared to when the moisture is less.

\subsection{Measures of instability}

Table 1 summarises the mean, standard deviation (std. dev.), maximum and minimum, for CAPE, CIN, PWC and VWS observed at $1730 \mathrm{hr}$ IST over Bangalore during pre-monsoon season. The mean CAPE, CIN, PWC at $1730 \mathrm{hr}$ IST are observed to be $1324,49.3 \mathrm{~J} / \mathrm{kg}$ and $30 \mathrm{~mm}$ respectively. The mean VWS is $-7.0 \times 10^{-3} \mathrm{~s}^{-1}$, while maximum and minimum are found to be 35.1 and $-27.8 \times$ $10^{-3} \mathrm{~s}^{-1}$ over this station.

\subsubsection{Variation of CAPE}

The box and whisker plots are drawn to show the variability of a thermodynamic parameter on a TSD and an NTSD. This plot divides the data into equal parts so that one fourth of the data is represented by each part. This is used for showing the minimum, first quartile (i.e., $25 \%$ of data has values less than this value), median, third quartile and the maximum values of a parameter. Figure 3 is the box and whisker of CAPE for the TSD and NTSD, respectively. This figure shows significant separation of CAPE on TSD from that of NTSD. The median CAPE shown by the horizontal line is $1423.8 \mathrm{~J} / \mathrm{kg}$ for TSD and $719 \mathrm{~J} / \mathrm{kg}$ for NTSD respectively. This suggests that higher (lower) values of CAPE are associated with TSD (NTSD). In other words, $50 \%$ of CAPE values are lying in

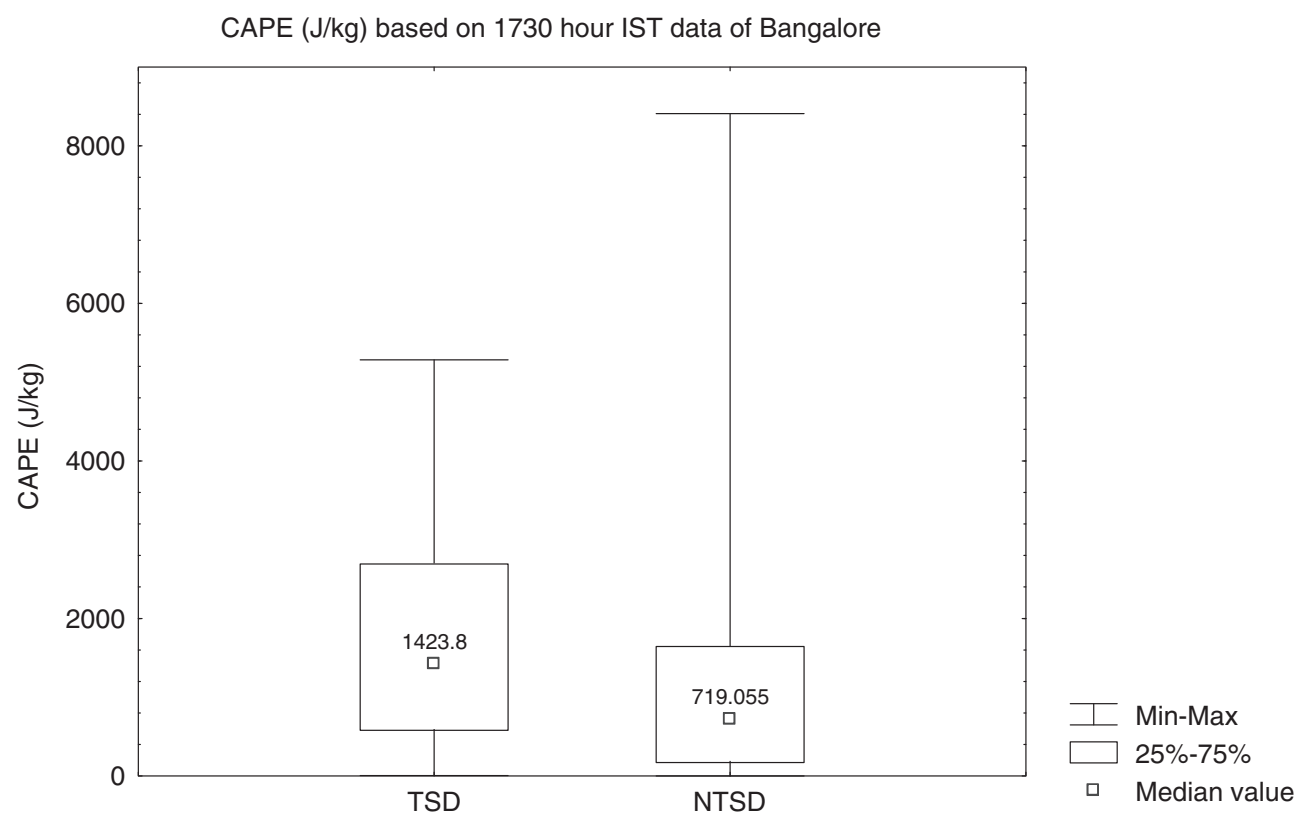

Figure 3. Box and whisker of CAPE $(\mathrm{J} / \mathrm{kg})$ for the TSD and NTSD. 
the higher range on TSD. The maximum value of CAPE on the TSD and NTSD was to be 5283 and $8410 \mathrm{~J} / \mathrm{kg}$. Despite a very high value of CAPE of $8410 \mathrm{~J} / \mathrm{kg}$ on 1 April 2003, shown by the upper whisker of NTSD, no convective activity occurred which is suggestive of the influence of large scale conditions in modulating the convective activity. This indicates that tropical convection is not only governed by the local features, but also influenced by large scale features. The minimum value of CAPE for a TSD over Bangalore is found to be as low as $5 \mathrm{~J} / \mathrm{kg}$, shown by the lower whisker, which was on 21 April 2004. Bhat (2002) has analysed the soundings during monsoon season over North Bay and found that CAPE builds up before convection, decreases by 2000-3000 J/kg during the periods of prolonged precipitation and then recovers again in 1-2 days time. On detailed analysis on the time of occurrence of thunderstorms, it was found that whenever a thunder event occurred before the time of routine ascent, it lead to the reduction in CAPE in the $1730 \mathrm{hr}$ IST soundings. On 21 April 2004, the thunder was reported during 1615-1630 hr IST at Bangalore city and during 1630-1750 hr IST by the Bangalore airport observatory leading to it's reduction at the time of observation. The CAPE and CIN on this day at $0530 \mathrm{hr}$ IST were 2198 and $33 \mathrm{~J} / \mathrm{kg}$ and decreased to 5 (191) $\mathrm{J} / \mathrm{kg}$ at 1730 hr IST suggesting that the atmosphere has already consumed the instability. This decrease in CAPE is attributed to cooling and drying of the atmosphere due to rainfall. The minimum value of CAPE on the NTSD, shown by the lower whisker, is $1 \mathrm{~J} / \mathrm{kg}$ on 7 April 2006 and is on expected lines indicating that lower CAPE is not a favourable condition for a storm to occur. The $Z_{x y}$ value for CAPE on the TSD and NTSD was found to be 3.8 which is statistically significant at $99 \%$ confidence (table 2 ). This parameter can be used for distinguishing between the two categories.

\subsubsection{Variation of CIN}

The box and whisker plot of CIN is shown in figure 4. The mean and sd of CIN is 46 and 66 $\mathrm{J} / \mathrm{kg}$ on the TSD and are 50 and $103 \mathrm{~J} / \mathrm{kg}$ on the NTSDs, respectively. Also, the median values in both the categories are nearly the same, i.e., 12.2 and $15.2 \mathrm{~J} / \mathrm{kg}$ suggesting that this parameter is not

Table 2. Table for $Z_{x y}$.

\begin{tabular}{llrcc}
\hline Sl. no. & & $Z_{x y}$ & $Z_{99}$ & $Z_{95}$ \\
\hline 1 & CAPE & 3.9 & \pm 2.56 & \pm 1.98 \\
2 & CIN & -0.8 & \pm 2.56 & \pm 1.98 \\
3 & PWC & 8.9 & \pm 2.56 & \pm 1.98 \\
4 & VWS & -4.2 & \pm 2.56 & \pm 1.98 \\
\hline
\end{tabular}

a very robust parameter for distinguishing a TSD from an NTSD. A high value of CIN (305 J/kg) was observed on $1730 \mathrm{hr}$ IST of 23 April 2000 which is a TSD. The $0530 \mathrm{hr}$ IST soundings indicated high CAPE of $3843 \mathrm{~J} / \mathrm{kg}$ and low CIN of $27 \mathrm{~J} / \mathrm{kg}$ suggesting the occurrence of TS. The thunderstorm events were reported from the city and airport observatories during late afternoon just before the routine $1730 \mathrm{hr}$ IST RS/RW ascent. The CAPE and CIN at $1730 \mathrm{hr}$ IST were 362 and $305 \mathrm{~J} / \mathrm{kg}$, respectively. High CIN (1220 J/kg) was observed on a NTSD respectively, which is on the expected lines that TSD are associated with low CIN and NTSD with high CIN. Also, zero CIN is found on TSD as well as NTSD. The presence of heat, low on almost all the days in pre-monsoon season over the southern Indian peninsula during this season (Srinivasan et al. 1973) acts as one of the factors that enhances instability and favours deep convection over this region. The $Z_{x y}$ is calculated to be -0.47 which is not significant at $95 \%$ confidence level.

\subsubsection{Variation of $P W C$}

The box and whisker plot of PWC is shown in figure 5 . This figure shows that median PWC are 39.9 and $26.9 \mathrm{~mm}$ for TSD and NTSD, respectively. It also shows that PWC on the TSD are higher as compared to that on NTSD respectively. This is consistent with the results of $\mathrm{T}_{\mathrm{d}}$ that TSD has higher water content as compared to the NTSD. The $Z_{x y}$ for PWC was found to be 12.7 which is statistically significant at $99 \%$ confidence level.

\subsubsection{Variation of vertical wind shear}

The VWS after buoyancy is the second most important parameter for the organisation and growth of a thunderstorm cell. The wind shear essentially determines the movement and life span besides pumping moisture into the storm. Weisman and Klemp (1982) have shown that the midlatitude storms that grow in an environment of low VWS $\left(<3 \times 10^{-3} \mathrm{~s}^{-1}\right)$ last for a short time, while moderate to high VWS $\left(3-5 \times 10^{-3} \mathrm{~s}^{-1},>5 \times\right.$ $10^{-3} \mathrm{~s}^{-1}$ ) results in the formation of multicells and supercells. According to Rasmussen and Wilhelmson (1983), the environments of low shear and low CAPE are conducive for non-rotating thunderstorms, while strong shear $\left(>3.5 \times 10^{-3} \mathrm{~s}^{-1}\right)$ and high CAPE $(>2500 \mathrm{~J} / \mathrm{kg})$ leads to tornadic storms. The scatter plot of VWS on TSD and NTSD is shown in figure 6(a) and box and whisker plot is shown in figure 6(b). It is seen from figure 6(a) that there is a large spread in the VWS on the TSD and NTSD. Most frequently occurring value of VWS on 


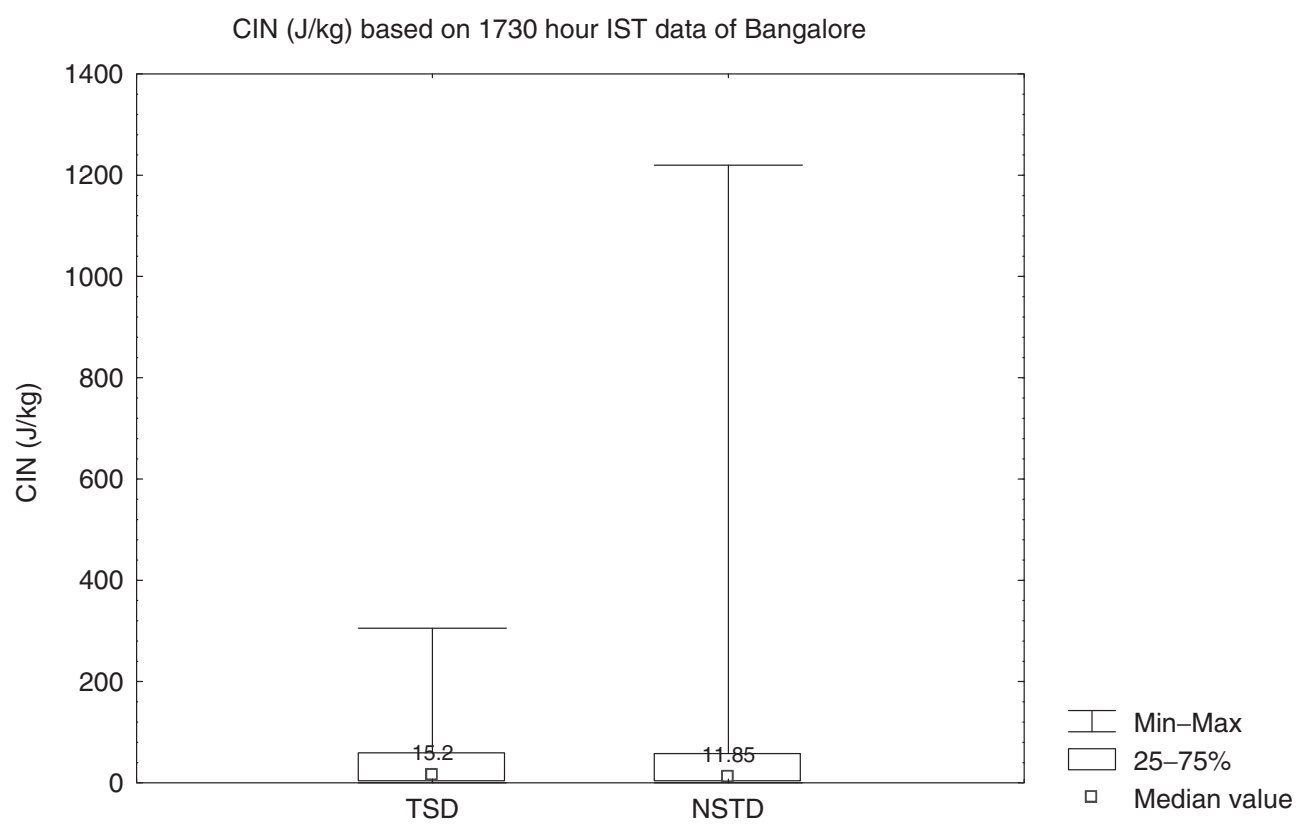

Figure 4. Box and whisker of CIN $(\mathrm{J} / \mathrm{kg})$ for the TSD and NTSD.

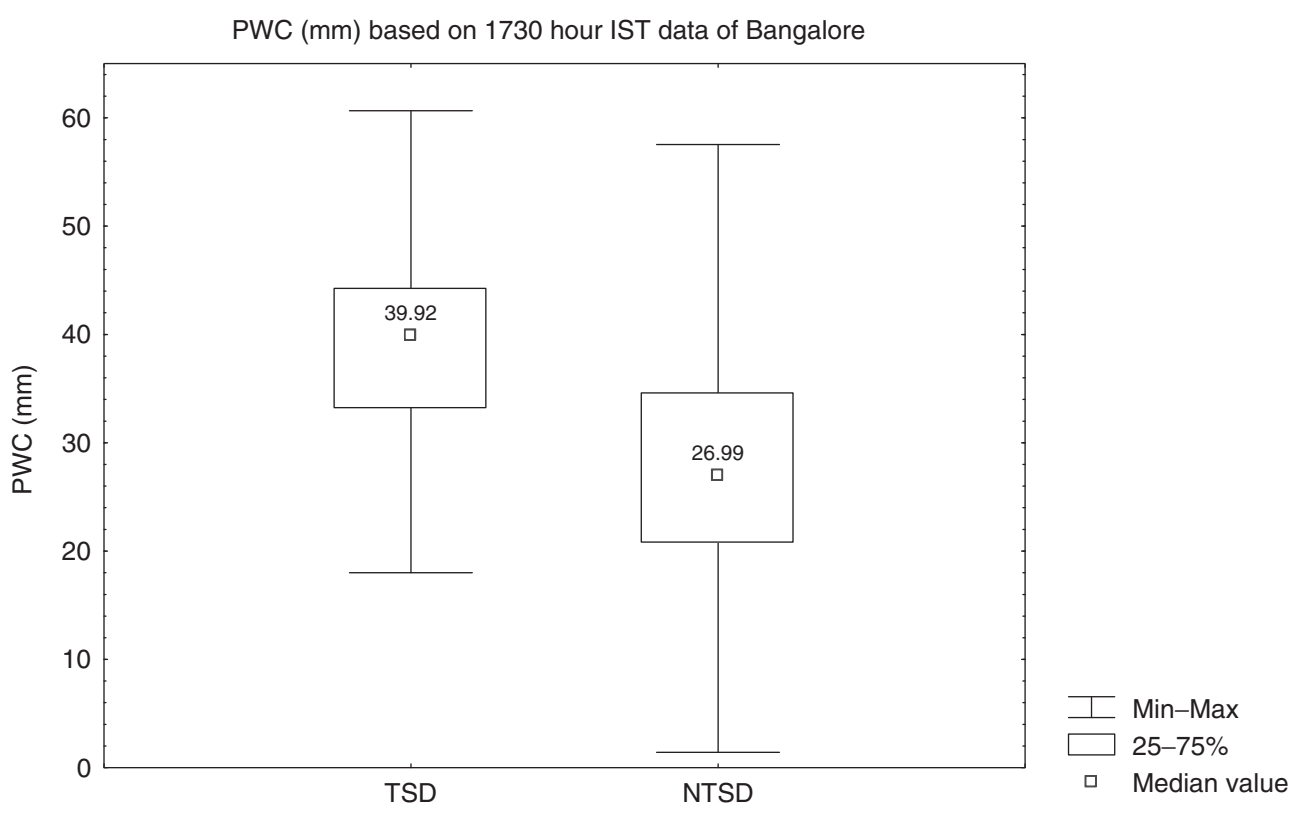

Figure 5. Box and whisker of PWC (mm) for the TSD and NTSD.

TSD and NTSD are found to be -5.8 and $4.3 \times$ $10^{-3} \mathrm{~s}^{-1}$ and the median values on these days were found to be -1.0 and $0.06 \times 10^{-3} \mathrm{~s}^{-1}$ respectively (figure $6 \mathrm{~b}$ ). The $Z_{x y}$ in this case was -4.2 which is statistically significant at $99 \%$ confidence level.

\subsection{Forecast skill of $C A P E$ and $P W C$}

The forecast skill of the above parameters whose means are statistically significant are tested using the data for 2 years from 2008 to 2009. During the pre-monsoon season of these years, there was $23 \%$ of TSD and $77 \%$ of NTSD. The probability of detection (POD), false alarm rate (FAR), critical success index (CSI) and Hiedke skill score (HSS) are used for testing the skill of the forecast (Wilks 1995). Contingency table was prepared by taking the median values of CAPE and PWC as $1423 \mathrm{~J} / \mathrm{kg}$ and $39 \mathrm{~mm}$ as the thresholds. Table 3 summarises the values of different scores calculated using the contingency table. During the pre-monsoon years of 2008-2009, CAPE and PWC data were available 


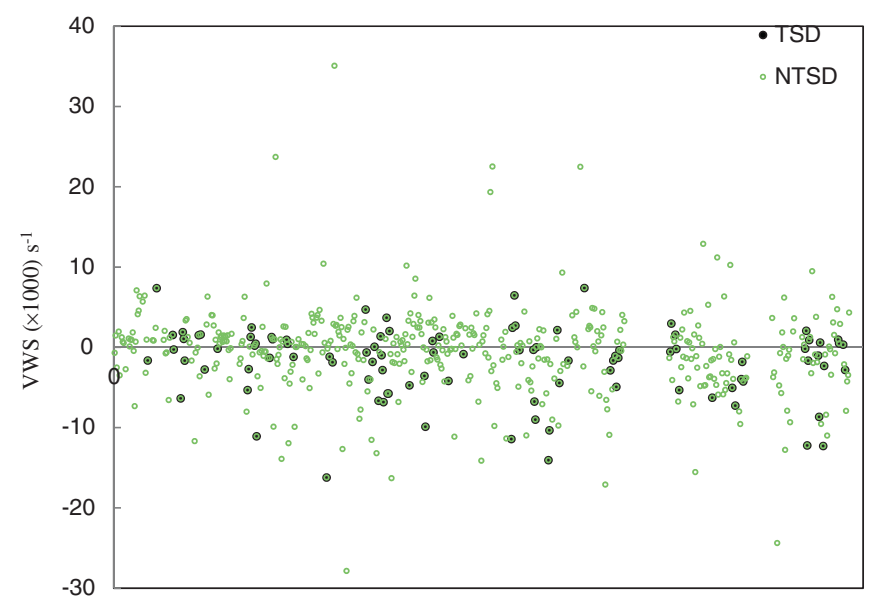

(a)

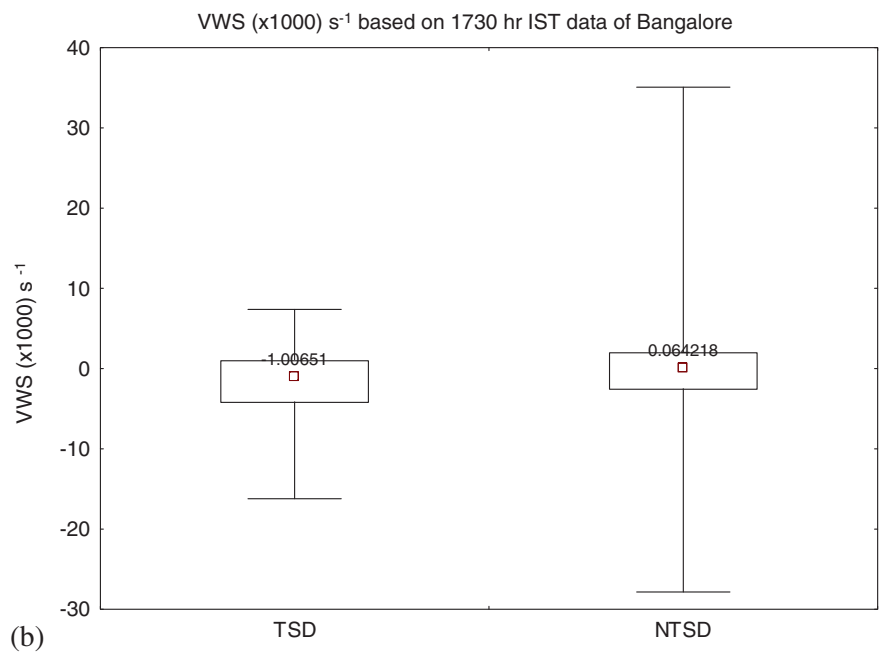

$\mp$ Max-Min
$\square$ 25-75\%
Median

Figure 6. (a) Scatter plot, (b) box and whisker plot of VWS $\left(\mathrm{s}^{-1} \times 1000\right)$ for the TSD and NTSD.

Table 3. Verification of prediction of thunderstorms at Bangalore using $1730 \mathrm{hr}$ IST data.

\begin{tabular}{lccc}
\hline & & \multicolumn{2}{c}{ Prediction } \\
\cline { 2 - 3 } Index & Observation & TSD & NTSD \\
\hline 1. CAPE $\geq 1423$ & TD & 21 & 05 \\
POD $=0.49, \mathrm{FAR}=0.51$, & NTD & 22 & 34 Total $=82$ days, TSD $=26$ \\
$\mathrm{CSI}=0.44, \mathrm{HSS}=0.35$ & & 21 & 06 \\
2. PWC $\geq 39$ & TD & 16 & 74 Total $=117$ days, TSD $=27$ \\
POD $=0.57, \mathrm{FAR}=0.43$, & NTD & & \\
CSI $=0.49, \mathrm{HSS}=0.53$ & & & \\
\hline
\end{tabular}

for 82 and 117 number of days respectively. POD, FAR, CSI and HSS are found to be 0.49, 0.51, 0.44 and 0.35 when CAPE is used as a predictor, whereas these scores are found to be $0.57,0.43$, 0.49 and 0.53 when PWC is used as a predictor. One of the difficulties in predicting the TSD using the CAPE is that the thunderstorms often occur between the times when the observations are not available (Colby 1984).

\section{Conclusions}

The motivation for this study is to investigate the difference of atmospheric parameters on the TSD and NTSDs respectively. Also, whether the sounding derived parameters like CAPE, CIN and PWC can give guidance for thunderstorm occurrence over Bangalore is also investigated. The main conclusions derived from this study are: 
- The atmosphere is cooled almost in the entire troposphere on the TSD with significant cooling in the lower troposphere. The maximum -ve and + ve departures at the surface are close to 2 and $0.5^{\circ} \mathrm{C}$ on the TSD and NTSDs respectively. Strong and +ve anomaly in $\mathrm{T}_{\mathrm{d}}$ is seen on the TSDs, while -ve anomaly is observed for NSTD over Bangalore during pre-monsoon. The test of significance shows that the difference of $\mathrm{T}$ and $\mathrm{T}_{\mathrm{d}}$ on TSD and NTSD are statistically significant at 99\% confidence level.

- The mean CAPE, CIN and PWC at $1730 \mathrm{hr}$ IST are found to be $1324,49.3 \mathrm{~J} / \mathrm{kg}$ and $30 \mathrm{~mm}$, respectively. The mean VWS is of the order of $-7 \times 10^{-3} \mathrm{~s}^{-1}$ over Bangalore in pre-monsoon season.

- Significant separation of CAPE on TSD from that of NTSD suggests that this parameter can distinguish a TSD from that of a NTSD. The median CAPE on TSD is found to be higher $(1423.8 \mathrm{~J} / \mathrm{kg})$ as compared to the NTSD median (719 J/kg). $Z_{x y}$ for CAPE was found to be 3.8 which is statistically significant at $99 \%$ confidence.

- The median CIN for TSD and NTSD are found to be nearly the same, i.e., 12.2 and $15.2 \mathrm{~J} / \mathrm{kg}$. The $Z_{x y}$ for CIN is found to be -0.47 which is not significant at $95 \%$ confidence level and hence this parameter is not a very robust parameter for distinguishing a TSD from an NTSD over Bangalore in pre-monsoon season.

- The median values of PWC and VWS are 39.9 and $26.9 \mathrm{~mm}$ and -1.0 and $0.06 \times 10^{-3} \mathrm{~s}^{-1}$ for TSD and NTSD respectively. The $Z_{x y}$ for PWC and VWS are found to be 12.7 and -4.2 which are statistically significant at $99 \%$ confidence level. Thus, these two parameters can also be used for distinguishing a TSD from that of a NTSD.

- The POD, FAR, CSI and HSS are found to be $0.49,0.51,0.44$ and 0.35 when CAPE is used as a predictor, whereas these scores are found to be $0.57,0.43,0.49$ and 0.53 , when PWC is used as a predictor.

\section{Acknowledgements}

The authors are thankful to the University of Wyoming for providing the upper air data and derived parameters on their website. The first author is thankful to the Director General of Meteorology, IMD, New Delhi and Deputy Director General of Meteorology, RMC, Chennai for their encouragement and support.

\section{References}

Agnihotri G 2014 Objective forecast of thundery and nonthundery days using conventional indices over Bangalore during pre-monsoon season; Mausam 65 205-214.
Agnihotri G, Venugopal R and Hatwar H R 2013 Climatology of thunderstorms and squalls over Bangalore; Mausam 64 735-740.

Bhat G S 2002 Near-surface variations and surface fluxes over the northern Bay of Bengal during the 1999 Indian summer monsoon; J. Geophys. Res. 107(D17) 4336.

Brooks H E, Lee J W and Crave J P 2003 The spatial distribution of severe thunderstorm and tornado environments from global reanalysis data; Atmos. Res. 67-68 73-94.

Chakrabarti D, Biswas H R, Das G K and Kore P A 2008 Observational aspects and analysis of events of severe thunderstorms during April and May 2006 for Assam and adjoining states - A case study on 'Pilot Storm Project'; Mausam 59 461-478.

Chaudhari H S, Sawaisarje G K, Ranalkar M R and Sen P N 2010 Thunderstorms over a tropical Indian station, Minicoy: Role of vertical wind shear; J. Earth Syst. Sci. 119(5) 603-615.

Colby F P 1984 Convective inhibition as the predictor of convection during AVE SESAME-2; Mon. Wea. Rev. 112 2239-2252.

Dalal S, Lohar D, Sarkar S, Sadhukhan I and Debnath G C 2012 Organisational modes of squall type mesoscale convective systems during pre-monsoon season over eastern India; Atmos. Res. 106 120-138.

Das S, Mohanty U C, Tyagi A, Sikka D R, Joseph P V, Rathore L S, Habib A, Baidya S, Sonam K and Sarkar A 2014 The SAARC Storm - A coordinated field experiment on severe thunderstorm observations and regional modelling over the South Asian region; Bull. Am. Meteor. Soc. $95603-617$.

Fadnavis F, Deshpande M, Ghude S D and Ernest Raj P 2014 Simulation of severe thunder storm event: A case study over Pune, India; Nat. Hazards 72 927-943.

Latha R and Murthy B S 2011 Boundary layer signatures of consecutive thunderstorms as observed by Doppler sodar over western India; Atmos. Res. 99 230-240.

Litta A J, Mohanty U C, Das S and Idicula S M 2012 Numerical simulation of severe local storms over east India using WRF-NMM mesoscale model; Atmos. Res. 116 160184.

Moncrieff M and Miller M J 1976 The dynamics and simulation of tropical cumulonimbus and squall lines; Quart. J. Roy. Meteor. Soc. 102 373-394.

Mukhopadhyay P, Mahakur M and Singh H A K 2009 The interaction of large scale and mesoscale environment leading to formation of intense thunderstorms over Kolkata. Part I: Doppler radar and satellite observations; J. Earth Syst. Sci. 118 441-466.

Pennelly C, Reuter G and Flesch T 2014 Verification of the WRF model for simulating heavy precipitation in Alberta; Atmos. Res. 135-136 172-192.

Rajeevan M, Kesarkar A, Thampi S B, Rao T N, Radhakrishna B and Rajasekhar M 2010 Sensitivity of WRF cloud microphysics to simulations of a severe thunderstorm event over southeast India; Ann. Geophys. 28(2) 603-619.

Rasmussen E N and Wilhelmson R B 1983 Relationships between storm characteristics and 1200 GMT hodographs, low-level shear, and stability; Preprints, 13th Conf. on Severe Local Storms, Tulsa, OK, Am. Meteor. Soc., J5-J8.

Singh C, Mohapatra M, Bandyopadhyay B K and Tyagi A 2011 Thunderstorm climatology over northeast and adjoining east India; Mausam 62 163-170.

Sinha V and Pradhan D 2006 Supercell storm at Kolkata, India and neighbourhood-analysis of thermodynamic conditions, evolution, structure and movement; Indian J. Radio Space Phys. 35 270-279. 
Srinivasan V, Ramamurthy K and Nene Y R 1973 Discussion of typical weather situations: Summer Nor'westers and Andhis and large scale convective activity over peninsula and central parts of the country; Forecasting Manual Report III-2.2, India Meteorological Department.

Tyagi A 2007 Thunderstorm climatology over Indian region; Mausam 58(2) 189-212.

Tyagi B, Satyanarayana A N V and Vissa N K 2013 Thermodynamical structure of atmosphere during premonsoon thunderstorm season over Kharagpur as revealed by STORM data; Pure Appl. Geophys. 170 675-687.

Weisman M L and Klemp J B 1982 The dependence of numerically simulated convective 500 storms on vertical shear and buoyancy; Mon. Wea. Rev. 110 504-520.
Wilks D S 1995 Statistical Methods in Atmospheric Sciences; Academic Press, San Diego, CA.

Yamane Y and Hayashi T 2006 Evaluation of environmental conditions for the formation of severe local storms across the Indian subcontinent; Geophys. Res. Lett. 33 L17806, doi: 10.1029/2006GL026823.

Yamane Y, Hayashi T, Dewan A M and Akter F 2010 Severe local convective storms in Bangladesh. Part II: Environmental conditions; Atmos. Res. 95 407418.

Yamane Y, Hayashi T, Kiguchi M, Mahmmood Fatima A and Mahmmood A D 2012 Synoptic situations of severe local convective storms during the pre-monsoon season in Bangladesh; Int. J. Climatol. 33(3) 725734. 